\title{
Mapping the intellectual and conceptual structure of physical education research: Direct citation analysis
}

\author{
Andrzej Lis ${ }^{\mathrm{ABCD}}$, Mateusz Tomanek ${ }^{\mathrm{CDE}}$ \\ Nicolaus Copernicus University in Toruń, Poland
}

Authors contribution: A - Study design; B - Data collection; C - Bibliometric analysis; D - Manuscript preparation; E- Funds collection

\begin{abstract}
Background The aim of the study is to identify and explore the intellectual and conceptual structure of physical education and Study research. It is focused around the following study questions: (1) What are the most influential publications Aim within the research field? (2) What are the research fronts in physical education studies?

Material and As a result of the research sampling process, the 10,334 publications indexed in the Scopus database were Methods selected by the title search for the phrase 'physical education'. Citation analysis, one of science mapping methods, was employed to conduct the analysis. The study process and the visualization of its findings were supported by the VOSviewer software. In the process of citation analysis, we used the following weight attributes: (1) custom weight attributes: the number of citations received by a document and the normalized of citations for a document, and (2) standard weight attributes: the number of citation links.

Results Firstly, the most prominent references have been pointed out and discussed. The study of the effects of the SPARK physical education program in regard to physical activity of elementary school pupils by Sallis et al. (1997) is found to be the most cited publication in the physical education research field. The systematic literature review and meta-analysis of research on application of self-determination theory in the physical education context by Vasconellos et al. (2020) is recognized as the publication of the highest value of the normalized number of citations. The application of self-determination theory of motivation in physical education is the topic attracting a lot of attention of the top cited publications in the field. The prominent and central position of these references is confirmed by the analysis of citation links. Secondly, the following research fronts in physical education studies have been identified: (1) motivation in physical education, (2) physical education programmes, (3) development of physical education, (4) self-determination in physical education, (5) physical education and students' academic achievement, (6) support of physical activity autonomy, (7) gender and physical education, and (8) long-term effects of physical education. Combining the research fronts identified with co-word analysis and direct citation analysis, the two-dimensional matrix mapping the conceptual structure of the physical education research field has been developed. The matrix categorizes publications according to their themes and the age of students / the levels of education, which are the object of the analysed studies.

Conclusions: The study contributes mainly to development of theory through mapping the scientific output within the physical education research field. Identification of core references provides valuable information for the scholars cultivating the field about the most recognized classical works receiving the highest number of citations and 'emerging stars' of the highest normalized number of citations. Such information is crucial for any theoretical reviews regarding the issues of physical education. Discovering research fronts points out the themes of the highest prominence and may be an indication for searching prospective research topics by authors. Developing the matrix to be used for mapping the conceptual structure of the research field is another contribution of the study.
\end{abstract}

Keywords: physical education, bibliometrics, science mapping, direct citation analysis.

\section{Introduction}

Discussing scenarios of physical education development, Kirk (2009) [1] "argues that multi-activity, sport based forms of physical education have been dominant in schools since the mid-twentieth century and that they have been highly resistant to change. The practice of physical education has focused on the transmission of de-contextualised sport-techniques to large classes of children who possess a range of interests and abilities, where learning rarely moves beyond introductory levels. Meanwhile, the academicization of physical education teacher education since the 1970s has left teachers less well prepared to teach this programme than they were

\footnotetext{
c) Andrzej Lis, Mateusz Tomanek, 2021

doi:10.15561/20755279.2021.0201
}

previously, suggesting that the futures of school physical education and physical education teacher education are intertwined". Multidimensionality of physical education studies and practice, and its importance for contemporary man encourages the ranks of researchers to cultivate the field, which contributes to its development. Nevertheless, in spite of the dynamic development of research in physical education, as observed by Tomanek and Lis (2020) [2], the research field has not been mapped from the bibliometric perspective, so far. There are very few studies covering the bibliometric analysis of the whole research field. What is more, some of them are limited to the time span covered by the analysis, e.g. the study by Fan and Gan (2010) [3], or they employ only simple bibliometric descriptive methodologies e.g. the research 
profiling study by Hinojo-Lucena et al. (2019) [4]. Taking into account these observations we assume that the identified gap in the body of knowledge remains unfilled and there is need for more bibliometric studies in the research field.

Thus, the aim of the study is to identify and explore the intellectual and conceptual structure in physical education research. It is focused around the following study questions: (1) What are the most influential publications within the research field? (2) What are the research fronts in physical education studies? The study employs the method of citation analysis for mapping the scientific output within the physical education research field. The remainder of the paper consists of three main chapters. Firstly, the research sampling process and the method of study are explained. Secondly, the results of bibliometric analysis are presented and visualized, paying attention to core references and research fronts. Thirdly, the research findings are discussed and interpretations are provided.

\section{Material and Methods}

Data Sources and Research Sample

We selected Scopus as a source of bibliometric data for

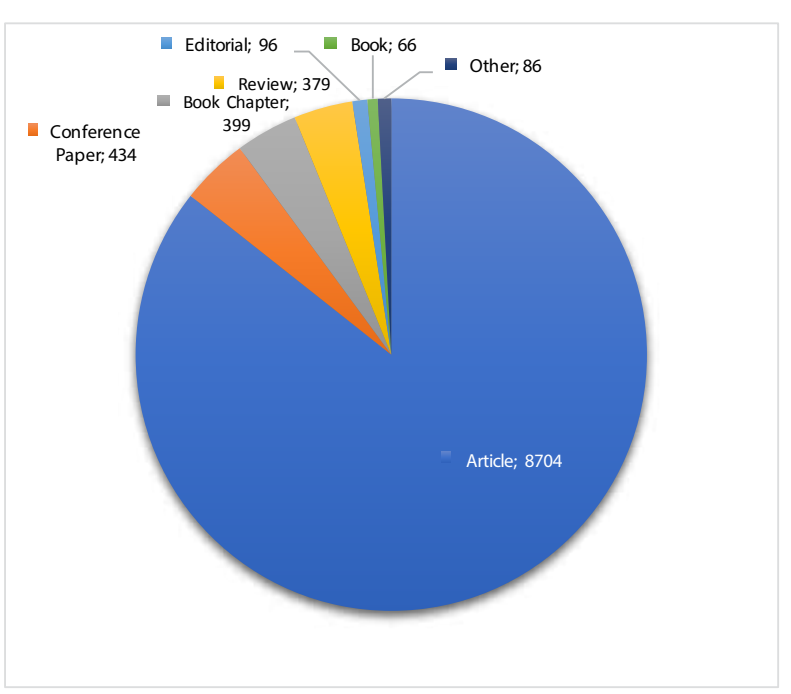

analysis. Besides Web of Science, Scopus is recognized as one of two leading, worldwide databases abstracting and indexing high-quality research publications $[5,6]$. In the procedure of research sampling, we searched for publications including phrase 'physical education' in their titles, regardless of a subject area or a date of publication. We purposely, replicated data sampling criteria used by Tomanek and Lis (2020) [2] in order to: (1) observe any changes in the field taking place in 2020, and (2) establish the conditions for comparing and contrasting research fronts identified by Tomanek and Lis (2020) [2] with the use of co-word analysis methodology [7] and our study based on direct citation analysis.

As of 15 December 2020, we retrieved 10,334 publications comprising the research sample. The majority of them are journal articles (8,704 items; 84.2\%), written in English $(8,115 ; 78.5 \%)$. The retrieved publications are distributed over twenty six non-exclusive subject areas, among which the most populated include: Social Sciences (6,150 items), Medicine (4,810), and Health Professions $(4,365)$. The detailed characteristics of the research sample in regard to the document types, publication languages and subject areas are presented in Figure 1.

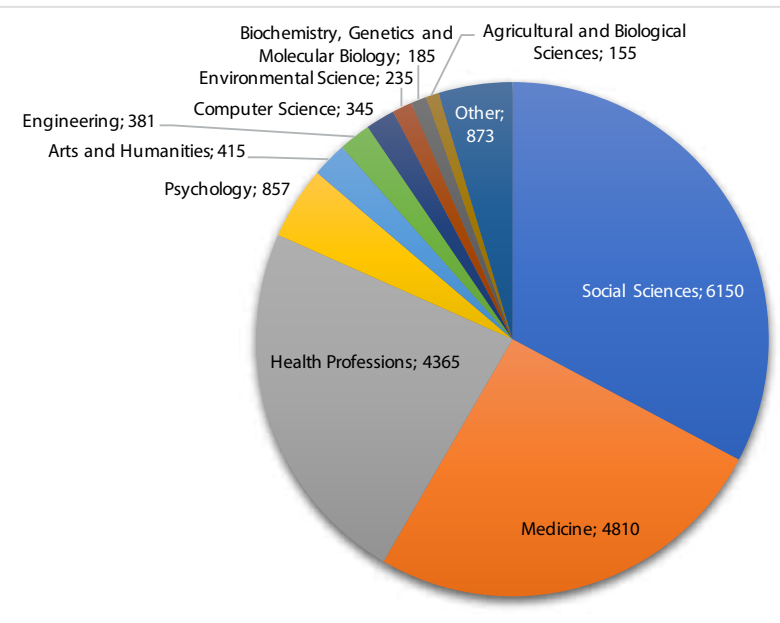

Figure 1. Characteristics of the research sample (by document type, language of publication, subject area): Source: Own study based on data retrieved from Scopus (15 December 2020). 
Comparing and contrasting the structure of the research sample with the characteristics of the sample retrieved in January 2020 by Tomanek and Lis (2020) [2] indicates no significant changes in regard to the type and language of publications, and represented subject areas.

Method of Study

Citation-based methods, which refer to relationships among the publications, are an important component of science mapping methodology. Citation based approaches include: direct citation (intercitation) analysis, bibliographic coupling and co-citation analysis [8]. In our study, we employed direct citation analysis [9], which is used to evaluate the influence of references on the research field by calculating the number of citations those references have received. In spite of its natural bias towards earlier publications, which have more chances to be cited than those recent ones, the method is recognized as an useful approach to identify the most influential works in the field [8]. In regard to discovering research fronts, although direct citation analysis shows lower accuracy in mapping science while comparing against bibliographic coupling and co-citation analysis [10], it is found to be more effective in discovering emerging research fronts [11]. Thus, considering all the strengths and weaknesses of the method, we decided to use direct citation analysis for the purpose of the study. The processes of analysis and visualization of findings were supported with VOSviewer software $[12,13]$. The association strength normalization method was used for analysis. Default values of layout and clustering parameters, with the exception of the minimum cluster size, were employed. The minimum number of items within a cluster was set as 100 for network analysis of the whole sample and 5 for network analysis of core references (meeting the threshold of 100 citations).

In the process of citation analysis, we used the following weight attributes: (1) custom weight attributes: the number of citations received by a document and the normalized number of citations for a document, and (2) standard weight attributes: the number of citation links.
The number of received citations manifests the interest of other scholars in a publication and its prominence in the field. In order to mitigate the natural bias of citation analysis toward older publications, we included into analysis the attribute of the normalized number of citations. "The normalized number of citations of a document equals the number of citations of the document divided by the average number of citations of all documents published in the same year and included in the data that is provided to VOSviewer. The normalization corrects for the fact that older documents have had more time to receive citations than more recent documents" [13, p. 37]. We assessed relatedness among the publications within the sample with the number of citation links. "A citation link is a link between two items where one items cites the other. Citation links are treated as undirect by VOSviewer. Hence, no distinction is made between a citation from item A to item B and a citation in the opposite direction" $[13$, p. 26].

\section{Results}

Core references

Among 10,334 publications included in the research sample, there are 6,452 items which were cited at least once. The threshold of 10 citations was attained by 2,189 publications, the threshold of 100 citations - by 118 publications. In the first step of analysis, we identified core references taking into account the criteria of the number of received citations, normalized citations and the number of citation links. As some of the analysed 10,334 publications were not connected to each other, we limited the analysis to the largest set of connect items consisting of 5,818 items. The catalogue of identified core references is provided in Table 1, and graphical visualization of citation analysis respectively in Figures $2-4$.

The study of the effects of the SPARK physical education program in regard to physical activity of elementary school pupils by Sallis et al. (1997) [14] is found to be the most cited publication in the research

Table 1. Core references in physical education research

\begin{tabular}{|c|c|c|c|c|c|}
\hline Citations & & Normalized Citations & & Citation Links & \\
\hline Reference & $\mathbf{N}$ & Reference & $\mathbf{N}$ & Reference & $\mathbf{N}$ \\
\hline Sallis et al. (1997) [14] & 592 & Vasconellos et al. (2020) [15] & 39.37 & Ntoumanis (2001) [16] & 204 \\
\hline Standage et al. (2005) [17] & 486 & D’elia (2019) [18] & 28.19 & Standage et al. (2005) [17] & 184 \\
\hline Standage et al. (2003) [19] & 478 & Rasberry et al. (2011) [20] & 26.55 & Standage et al. (2003) [19] & 180 \\
\hline Ntoumanis (2001) [16] & 474 & Sallis et al. (1997) [14] & 20.48 & Ntoumanis (2005) [21] & 180 \\
\hline Ntoumanis (2005) [21] & 397 & Sallis (1991) [22] & 19.95 & Vasconellos et al. (2020) [15] & 175 \\
\hline Sallis (1991) [22] & 365 & Henry (1978) [23] & 18.33 & Goudas et al. (1994) [24] & 167 \\
\hline $\begin{array}{l}\text { Trudeau and Shephard } \\
\text { (2008) [25] }\end{array}$ & 359 & Corder (1966) [26] & 17.91 & Sallis (1991) [22] & 164 \\
\hline Kirk (2009) [1] & 350 & $\begin{array}{l}\text { Staiano and Calvert (2011) } \\
\text { [27] }\end{array}$ & 17.58 & Sallis et al. (1997) [14] & 149 \\
\hline Bailey (2006) [28] & 338 & Wilson et al. (2020) [29] & 16.87 & Bailey et al. (2009) [30] & 137 \\
\hline Coe et al. (2006) [31] & 333 & Kirk (2013) [32] & 15.81 & Sallis et al. (2012) [33] & 130 \\
\hline
\end{tabular}

Source: Own study based on data retrieved from Scopus and analysed with VOSviewer (15 December 2020). 


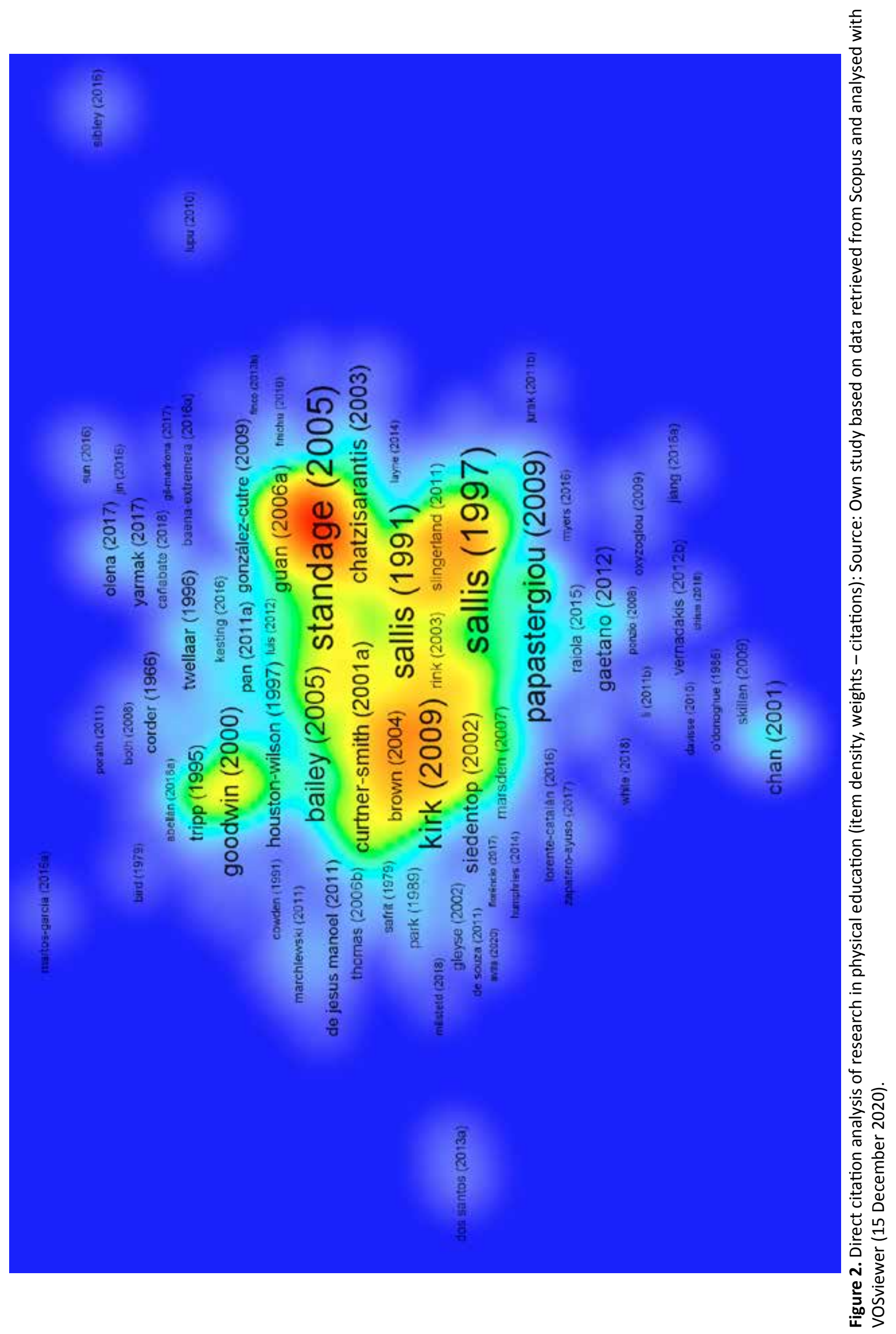




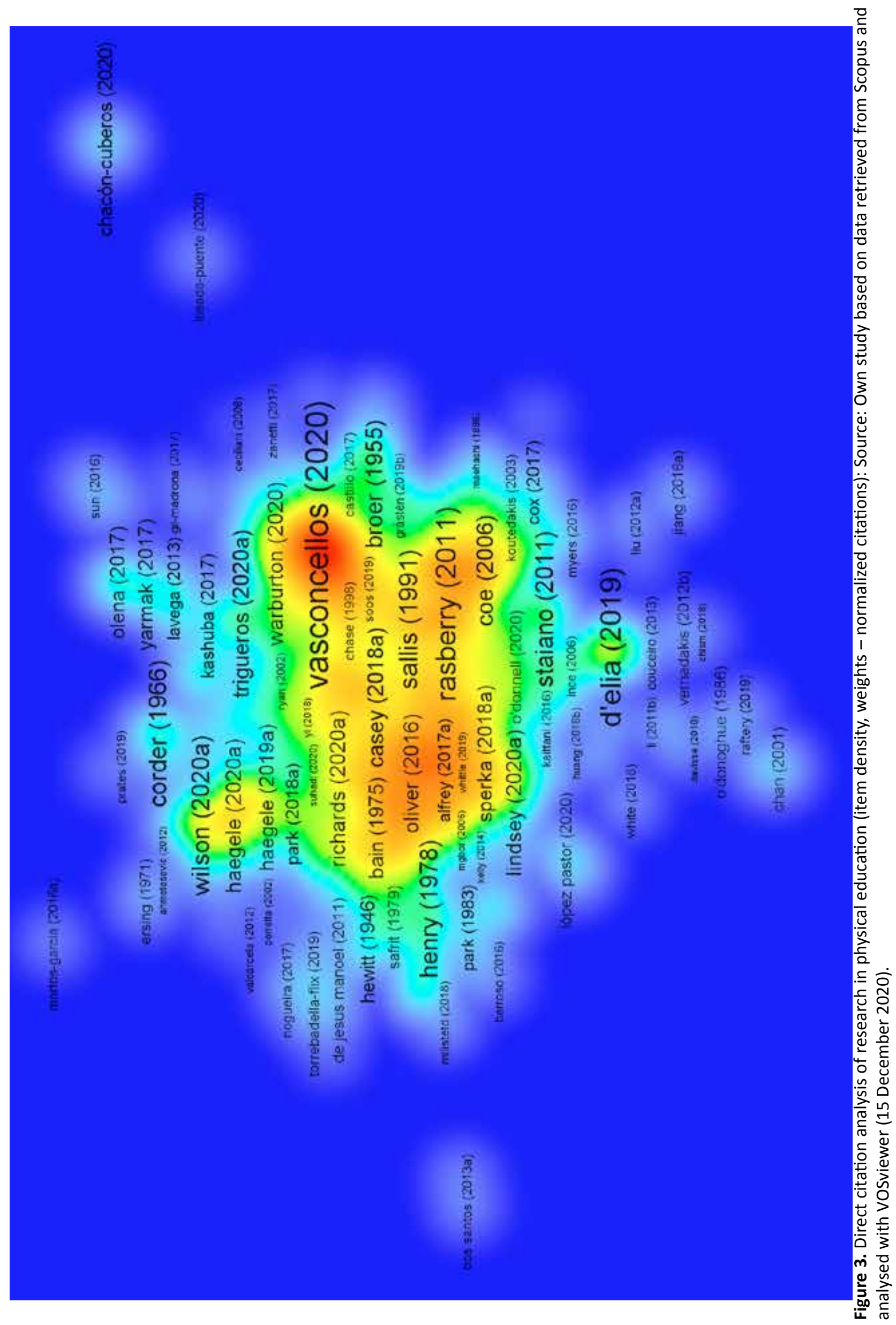




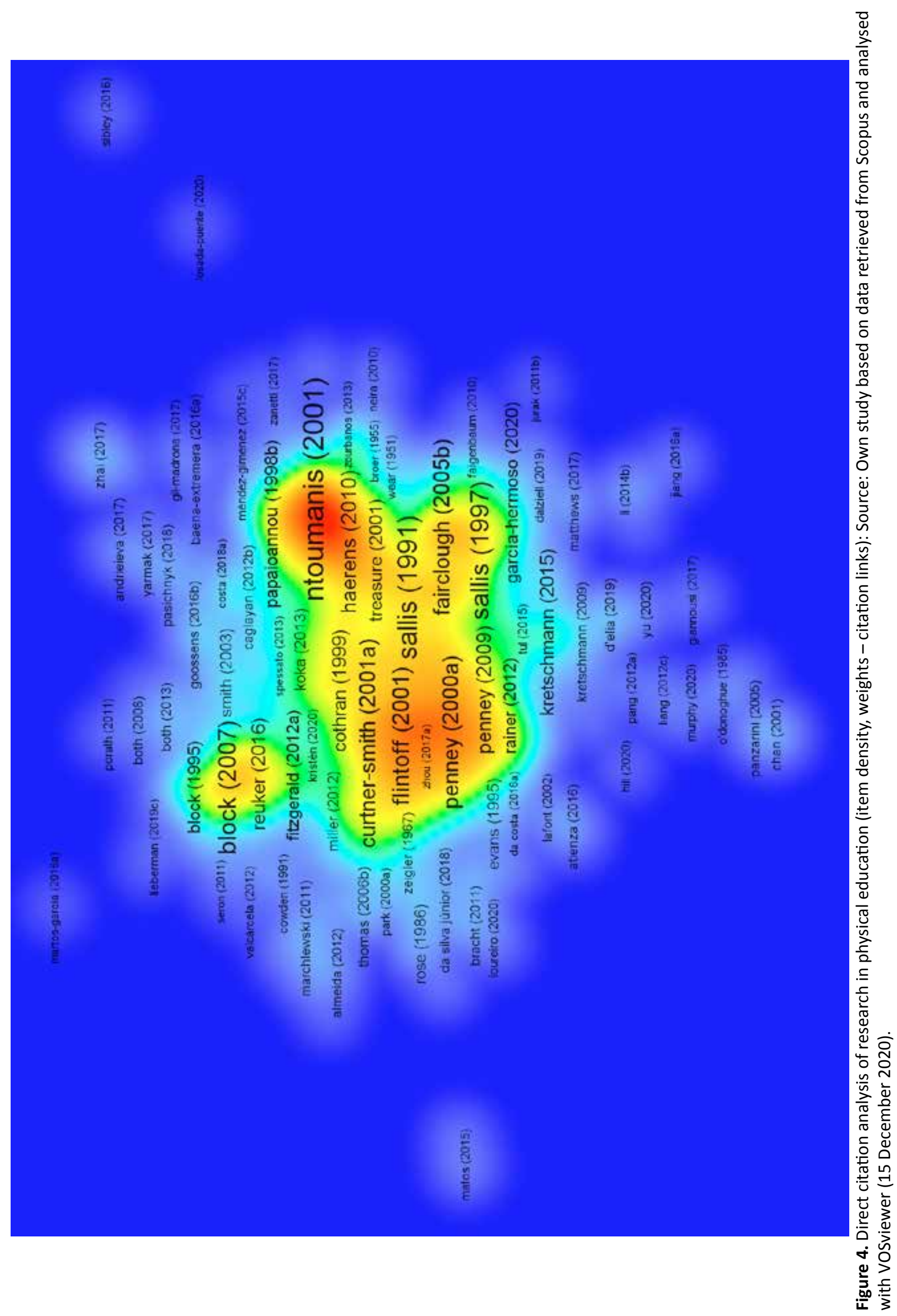


field. The followers are the works dealing with selfdetermination theory in physical education written by: Standage et al. (2005) [17], Standage et al. (2003) [19], Ntoumanis (2001) [16], and Ntoumanis (2005) [21]. Standage et al. (2005) [17] test self-determination theory based motivation in physical education in the context of the British secondary school. In their earlier study, Standage et al. (2003) [19] investigate the motivation of students to actively participate in physical education activities with the use of a model based on the assumptions of selfdetermination theory and achievement goal theory. The studies by Ntoumanis focused on "[a] self-determination approach to the understanding of motivation in physical education" [16] and "participation in optional school physical education using a self-determination theory framework" [21] are additional examples of research interest in the issues related to self-determination theory of human motivation in the context of physical education. The outcomes of physical activity for students' health and social behaviours as well as their school performance constitute the second stream of interest of the most cited publications. Sallis (1991) [22] investigates the role of physical activity for children's health. Trudeau and Shephard (2008) [25] conduct a systematic literature review aimed at investigating the impact of allocating additional times for physical education, physical activity and school sports on academic performance. Coe et al. (2006) [31] analyse the "[e]ffect of physical education and activity levels on academic achievement on children". Bailey (2006) explores the benefits from physical education and sport for students and educational systems. Last but not least, Kirk (2009) [1] develops scenarios of the future of physical education.

As already mentioned, in order to mitigate the bias of citation analysis to older publication, which have more opportunities to receive citations, we used for analysis the attribute of the normalized number of citations. The findings make a mixture of some very recent documents (2019-2020), highly cited publications from the 1990s and the 2010s and some older items dated as of the 1960s and the 1970s. Among the latest works, Vasconellos et al. (2020) [15] conduct the systematic literature review and meta-analysis of research on application of selfdetermination theory in the physical education context. D'elia (2019) [18] analyse and develop recommendations for curricula of the courses for physical education teachers from Italian primary schools. Wilson et al. (2020) [29] discuss the case of the U.S. mandate on "the least restrictive environment in physical educations". The second category includes the already mentioned works by Sallis (1991) [22] and Sallis et al. (1997), as well as the studies by Rasberry et al. (2011) [20], Staiano and Calvert (2011) [27], and Kirk (2013) [32]. Rasberry et al. (2011) [20] revise the scientific output investigating the relationship between physical activity and academic performance. Staiano and Calvert (2011) [27] explore the benefits from digital games combined with physical activity, the so-called 'exergames'. Kirk (2013) [32] analyses "[e]ducational value and models-based practice in physical education". It is interesting that some older publications such as the treatise on "[t]he academic discipline of physical education" by Henry (1978) [23] and the study of physical education effects on development of "educable mentally retarded boys" by Corder (1966) [26] are found among the publications of the highest value of the normalized number of citations.

Taking into account the number of citation links within the research sample, the Ntoumanis' study of "[a] self-determination approach to the understanding of motivation in physical education" [16] is identified as the top achiever. The followers are the already discussed publications focused on self-determination theory of motivation such as: Standage et al. (2005) [17], Standage et al. (2003) [19], Ntoumanis (2005) [21], and Vasconellos et al. (2020) [15]. Goudas et al. (1994) [24] "examined the relationships of perceived autonomy, perceived competence and goal orientations with intrinsic interests across two PE activities". Bailey et al. (2009) [30] revise the benefits from physical education and sport for physical, social, affective and cognitive domains. The catalogue of the most linked publications within the sample is completed by the aforementioned works by: Sallis et al. (1997) [14], Sallis (1991) [22], and the article revisiting the discussion on the role of physical education in public health by Sallis et al. (2012) [33].

\section{Research fronts}

In the second step of analysis, we focused on identifying research fronts within the field. We employed the network visualization function of VOSviewer (with default parameters) to display the groupings of publications within the field (Figure 5). 5,818 items taken for analysis are distributed over 26 clusters numbering from 103 items (the smallest one) to 459 items (the largest one).

In order to analyse thoroughly the research fronts in the field, we selected the core references with a minimum number of 100 citations per document. For each of 118 publications, the number of citation links was calculated. As some of the identified items were not connected to each other, the largest set consisting of 103 connected items was taken for further network analysis in order to map the interconnected clusters used for discovering research fronts (Figure 6). The structure of the identified clusters is detailed in Table 2.

Cluster 1, labelled as 'motivation in physical education', includes publications mainly from education and psychology journals. It shows strong links with the clusters dealing with the issues of delf-determination (Cluster 4) and autonomy (Cluster 6). It results from the assumptions of self-determination theory, which state that in order to motivate students to actively participate in physical education, it is critical to support meeting their innate, psychological needs in regard to autonomy, competence and relationships [52]. The most cited publication in the cluster, authored by Standage et al. (2005) [17], studies the model of motivation based on self-determination theory and indicates that "students who perceived a need-supporting environment 


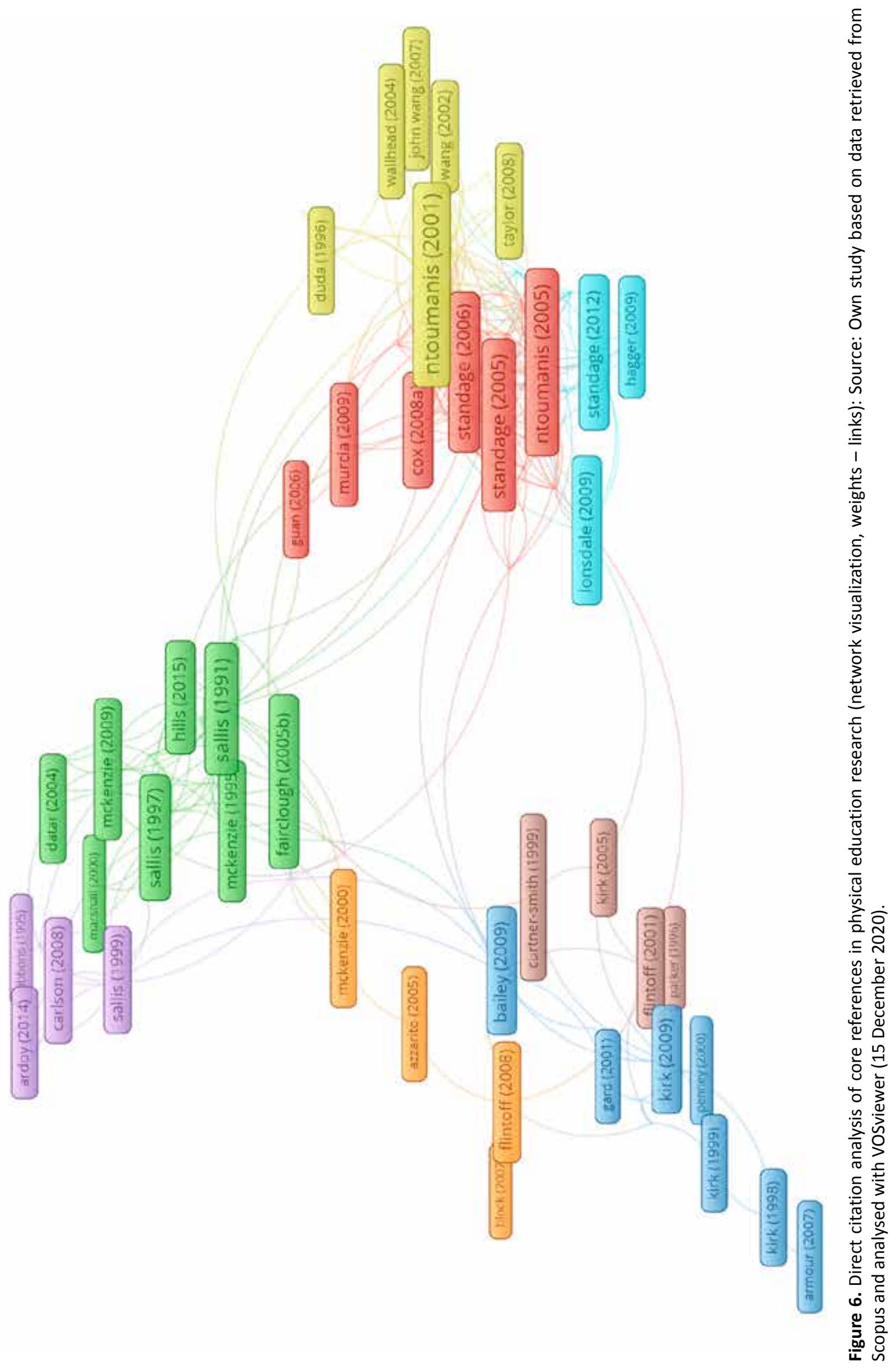


experienced greater levels of need satisfaction" [17, p. 411.]. In an earlier study, Standage et al. (2003) [19] focus on predicting students' intentions to take part in physical education activities with the use of constructs of achievement goal theory and self-determination theory. Numerous publications in Cluster 1 employ the technique of structural equation modelling (SEM). The example is the study by Haerens et al. (2015) [42], who "examined the mediating role of students' experiences of need satisfaction and need frustration in associations between perceived teaching style and students' motivation and oppositional defiance in the context of physical education"
[42, p. 26].

Cluster 2 is focused on 'physical education programmes'. Sallis et al. (1997) [14], the most cited reference within the sample, provide the assessment of the health promoting physical education programme aimed at increasing physical activity of students during both in-school physical education classes and outside of the school. According to the authors, combining physical education and health education may result in more intensive physical activity during the schooling period and after. The emphasis on the advantages of matching physical education with health programmes is observed

Table 2. Clusters of core references in physical education research

\section{Cluster number / label / colour / number of items \\ Cluster 1 / 'motivation in physical education' / red / $\mathrm{N}=22$}

Cluster 2 / 'physical education programmes' / green / $\mathrm{N}=21$

Cluster 3 / 'development of physical education' / blue / $\mathrm{N}=15$

\section{Cluster 4/ 'self-}

determination' in physical education' / yellow / $\mathrm{N}=15$

\begin{tabular}{|c|c|}
\hline $\begin{array}{l}\text { Cluster 5/ 'physical } \\
\text { education and students' } \\
\text { academic achievement' / } \\
\text { violet / N=9 }\end{array}$ & $\begin{array}{l}\text { Ardoy et al. (2014) [96]; Bailey (2006) [28]; Carlson et al. (2008) [97]; Coe et al. } \\
\text { (2006) [31]; Fairclough and Stratton (2005) [98]; Gibbons et al. (1995) [99]; Rasberry } \\
\text { et al. (2011) [20]; Sallis et al. (1999) [100]; Trudeau and Shephard (2008) [25] }\end{array}$ \\
\hline $\begin{array}{l}\text { Cluster } 6 / \text { 'support of } \\
\text { physical activity autonomy' } \\
\text { / light blue / } \mathrm{N}=7\end{array}$ & $\begin{array}{l}\text { Chatzisarantis et al. (2003) [101]; Hagger et al. (2003) [102]; Hagger et al. (2005) } \\
\text { [103]; Hagger et al. (2009) [104]; Lim and Wang (2009) [105]; Lonsdale et al. (2009) } \\
\text { [106]; Standage et al. (2012) [107] }\end{array}$ \\
\hline $\begin{array}{l}\text { Cluster } 7 \text { / 'gender and } \\
\text { physical education' / } \\
\text { orange / } \mathrm{N}=7\end{array}$ & $\begin{array}{l}\text { Azzarito and Solomon (2005) [108]; Block and Obrusnikova (2007) [109]; Cockburn } \\
\text { and Clarke (2002) [110]; Flintoff et al. (2008) [111]; Garrett (2004) [112]; Goodwin } \\
\text { and Watkinson (2000) [113]; McKenzie et al. (2000) [114] }\end{array}$ \\
\hline $\begin{array}{l}\text { Cluster } 8 \text { / 'long term } \\
\text { effects of physical } \\
\text { education' / brown / } \mathrm{N}=7\end{array}$ & $\begin{array}{l}\text { Curtner-Smith (1999) [115]; Curtner-Smith (2001) [116]; Enright and O'Sullivan } \\
\text { (2010) [117]; Flinton and Scraton (2001) [118]; Kirk (2005) [119]; McKenzie et al. } \\
\text { (1997) [120]; Parker (1996) [121] }\end{array}$ \\
\hline
\end{tabular}

\section{References}

Boiche et al. (2008) [34]; Cheon et al. (2012) [35]; Cox et al. (2008) [36]; Cox and Williams (2008) [37]; Ferrer-Caja and Weiss (2000) [38]; Guan et al. (2006) [39]; Haerens et al. (2010) [40]; Haerens et al. (2013) [41]; Haerens et al. (2015) [42]; Mouratidis et al. (2008) [43]; Murcia et al. (2009) [44]; Ntoumanis (2002) [45]; Ntoumanis et al. (2004) [46]; Ntoumanis (2005) [21]; Ntoumanis and Standage (2009) [47]; Standage et al. (2003) [19]; Standage et al. (2005) [17]; Standage et al. (2006) [48]; Taylor and Ntoumanis (2007) [49]; Taylor et al. (2010) [50]; Tessier et al. (2010) [51]; Van den Berghe (2010) [52]

Belsky et al. (2003) [53]; Burgeson et al. (2001) [54]; Cawleya et al. (2007) [55]; Datar and Sturm (2004) [56]; Fairclough and Stratton (2005) [57]; Hills et al. (2015) [58]; Lee et al. (2007) [59]; Lonsdale et al. (2013) [60]; Marshall and Hardman (2000) [61]; McKenzie et al. (1995) [62]; McKenzie et al. (1996) [63]; McKenzie et al. (2004) [64]; McKenzie and Lounsbery (2009) [65]; Morgan and Hansen (2008) [66]; Nettlefold et al. (2011) [67]; Sallis (1991) [22]; Sallis et al. (1993) [68]; Sallis et al. (1997) [14]; Sallis et al. (2012) [33]; Trudeau et al. (1999) [69]; Van Beurden et al. (2003) [70]

Armour and Yelling (2004) [71]; Armour and Yelling (2007) [72]; Bailey (2005) [73]; Bailey et al. (2009) [30]; Gard and Wright (2001) [74]; Gorely et al. (2003) [75]; Kirk and Colquhoun (1989) [76]; Kirk and MacDonald (1998) [77]; Kirk (1999) [78]; Kirk (2006) [79]; Kirk (2009) [1]; Kirk (2013) [32]; Light (2008) [80]; Penney and Chandler (2000) [81]; Siedentop (2002) [82]

Digelidis et al. (2003) [83]; Duda (1996) [84]; Goudas et al. (1994) [24]; Goudas and Biddle (1994) [85]; Ntoumanis (2001) [16]; Papaioannou (1994) [86]; Papaioannou (2004) [87]; Solmon (1996) [88]; Standage and Treasure (2002) [89]; Standage et al. (2003) [90]; Taylor et al. (2008) [91]; Treasure and Roberts (1995) [92]; Wallhead Ardoy et al. (2014) [96]; Bailey (2006) [28]; Carlson et al. (2008) [97]; Coe et al. (2006) [31]; Fairclough and Stratton (2005) [98]; Gibbons et al. (1995) [99]; Rasberry (100]; Trudeau and Shephard (2008) [25]

[103]; Hagger et al. (2009) [104]; Lim and Wang (2009) [105]; Lonsdale et al. (2009) [106]; Standage et al. (2012) [107]

Azzarito and Solomon (2005) [108]; Block and Obrusnikova (2007) [109]; Cockburn and Clarke (2002) [110]; Flintoff et al. (2008) [111]; Garrett (2004) [112]; Goodwin and Watkinson (2000) [113]; McKenzie et al. (2000) [114] (2010) [117]; Flinton and Scraton (2001) [118]; Kirk (2005) [119]; McKenzie et al. (1997) [120]; Parker (1996) [121]

Source: Own study based on data retrieved from Scopus and analysed with VOSviewer (15 December 2020). 
as well by Sallis (1991) [22], who claims that public health subject matter experts should be invited to design and assess school physical education programmes. Lee et al. (2007) [59], who analysed the reports of the American Centers for Disease Control and Prevention conducting the studies of school health policies and programs, notice that a significant part of schools were not conducting everyday physical education classes or released students from taking part in these classes. Another problem was associated with the career development paths of physical education teachers. Some of the states provided training programmes, which mismatched with the teachers' needs. In regard to education programmes, Morgan and Hansen (2008) [66] identify the barriers to teaching physical education programmes. What is interesting, institutional barriers and the factors out of teachers' control are recognized as the most thorny issues resulting in shortening physical education classes or poor quality of the classes.

Cluster 3, labelled as 'development of physical education', is centred around future directions of development of physical education and physical education teachers. Kirk (2009) [1] asks a rhetoric but fundamental question "Can we imagine a future in which physical education in schools no longer exists?". This question becomes particularly important nowadays, during the COVID-19 pandemic and on-line distance learning. Moreover, Kirk (2009) [1] highlights the relationship between education of future physical education teachers and trainers, and quality of physical education classes at schools. In this context, a forced shift to distance learning in physical education teachers' programmes and lack of internships at schools, due to the pandemic, may result in a lower level of knowledge, skills and social competencies of future physical education teachers. Thus, professional development of physical education teachers is the issue of paramount importance. Among studied publications within Cluster 3, Armour and Yelling (2004) [71] review the theory and research in the field of continuing professional development (CPD), and provide recommendations for developing a more effective model of professional development dedicated to physical education teachers (PE-CPD).

Cluster 4, labelled as 'self-determination in physical education', includes publications, which employ selfdetermination theory in the physical education context. The cluster shows spatial proximity and strong relatedness with Cluster 1 ('motivation in physical education') and Cluster 6 ('support of physical activity autonomy'). Referring to the work by Ames (1992) [122] dealing with the motivational climate within a classroom, Papaioannou (1994) [86] develops a questionnaire to measure the students' perception of their achievement orientation in physical education. Ntoumanis (2001) [16] concentrates on testing motivational processes among teenagers. The study takes into account social aspects, psychological mediators, various types of motivation and consequences. Goudas et al. (1994) [24] investigate "the relationships of perceived autonomy, perceived competence and goal orientations with intrinsic interest across two PE activities" [24, p. 453]. Taylor et al. (2008) [91] examine how motivational strategies employed by physical education teachers can influence self-determination of their students. This study refers as well to the level of fulfilment of teachers' psychological needs and notices that "factors that influence teacher motivation may also indirectly affect their motivational strategies toward students" [91, p. 75].

Cluster 5, labelled as 'physical education and students' academic achievement', focuses on discussing positive outcomes of physical activity of children. The studied publications point out two main benefits of physical education related to improvements in health condition and academic achievement. Effectiveness of physical activity influence on achieving health objectives is explained by Fairclough and Stratton (2005) [98]. The benefits from physical education and sport are also discussed by Bailey (2006) [28], who highlights that positive effects of physical education are strongly mediated by relationships (engagement) between students and teachers, trainers and parents in addition to participation in physical activity. The influence of physical education and physical activity on academic achievement is studied by Trudeau and Shephard (2008) [25], whose article is the most cited reference within the cluster. They point out that physical activity shows positive relationship with academic achievement but physical fitness is not directly related with students' grades. Coe et al. (2006) [31] investigate students' engagement in physical education classes and grades they receive. Their study of 214 participants shows that students of 'vigorous physical activity' received better grades. What is interesting, they notice that " $[\mathrm{m}]$ oderate physical activity did not affect grades" [31, p. 1515]. Carlson et al. (2008) [97] researched more than 5,300 participants to test whether there are any relationships between academic achievement and physical education classes. They point out that more participation in physical education may contribute to better grades in mathematics and reading. What is worth mentioning, "a small but significant benefit" was noticed only among girls [97, p. 721].

Cluster 6, labelled as 'support of physical activity autonomy', concentrates on promoting physical activity in leisure time. This aspect is mainly realized in the psychological context, which is also highlighted by the leading themes of the journals publishing references included in the cluster. Hagger et al. (2003) [102] notice positive effects of the "trans-contextual model indicating that perceived autonomy support in an educational context influences motivation in a leisure-time context" [102, p. 784]. In their earlier study, Hagger et al. (2005) [103] examine "replicability and cross-cultural invariance of a trans-contextual model of motivation", which assumes that "perceived autonomy support [...] in physical education [...] predicts autonomous motivation, intentions, and behaviour in a leisure time $[\ldots]$ physical activity context" [103, p. 376]. An interesting innovation among research collected in Cluster 6 is the employment of pedometers 
as a supplement of traditional questionnaire surveys. For instance, in the study conducted by Standage et al. (2012) [107], almost 500 students were using pedometers for four days to measure their physical activity in leisure-time.

Cluster 7, labelled as 'gender and physical education', explores the issues related to gender differentiation in physical activity. Garrett (2004) [112] makes an attempt to explain why girls give up physical activity in various stages of their lives and they consider physical education classes as a 'problem'. An interesting assumption is made by Azzarito and Solomon (2005) [108], who claim it is physical education programme rather gender, race and social class standing behind decrease in physical activity among the youth. They recommend that "schooling should carry the responsibility of educating children to adopt and maintain a physically active lifestyle" [108, p. 25]. Cockburn and Clarke (2002) [110] point out the contrast between "the polarized images of 'tomboy' and 'girlie"" among girls practising sports, which forces them to "creating 'double identities' and living 'split lives"” [110, p. 651].

Cluster 8, labelled as 'long-term effects of physical education', is focused on analysis of the learning outcomes of physical education programmes in the longterm perspective. McKenzie et al. (1997) [120] conducted 4-year studies investigating how various groups of teachers influence quantity and quality of classes. Curtner-Smith (1999) [115] analyses the differences in interpretations of the National Curriculum Physical Education (NCPE) by British teachers of physical education in regard to their experience, gender, age and the level of physical activity. What is interesting, as indicated by Kirk (2005) [119], the newly implemented PESSCLS strategy promoting the life-long physical activity was found to be ineffective in spite of significant financial resources spent on it. The cluster includes as well the studies of relationships between educating teachers in higher education institutions and prospective ways of teaching physical education in primary schools [116]. The study by Enright and O'Sullivan (2010) [117] goes beyond investing the impacts of governmental regulations or training of future physical education teachers and it focuses on involving students in decisions regarding the content of physical education classes. As observed by the authors, such practices increase significantly students' engagement and willingness to maintain physical activity.

\section{Discussion}

The results of the thematic mapping of the physical education research field, completed with the use of direct citation analysis, may be compared and contrasted with the study by Tomanek and Lis (2020) [2], which identifies leading thematic areas and emerging topics through cooccurrence analysis of high-frequency keywords (an example of co-word analysis). In order to optimise the conditions for the comparative analysis of research fronts, firstly, we purposely replicated data sampling criteria used in their study by Tomanek and Lis (2020) [2], and secondly, we employed the same software (VOSviewer) to support data analysis and findings visualisation

Thematic clusters identified with the use of co-word analysis focus on such issues as: "(1) "physical education didactics', (2) 'physical activity of school pupils', (3) 'physical education of adolescents', (4) 'human motor competence', (5) 'physical activity of adults"” [2]. At first sight, they seem to be very different from the findings from this study employing the method of direct citation analysis. For instance, in the current study, there is no categorization of clusters in regard to the age of participants of physical education as it was in the coword analysis (e.g. school pupils, adolescents, adults). Nevertheless, a deeper analysis reveals that the topics discussed by publications comprising Cluster 2 ('physical education programmes') are close to those included in Cluster 1 ('physical education didactics') in the study by Tomanek and Lis (2020) [2]. Moreover, combing these two studies together, the two-dimensional matrix mapping the conceptual structure of the physical education research field may be developed (Figure 7).

In Figure 7, the vertical axis reflects the age groups recognized as units of analysis in the study by Tomanek and Lis (2020) [2], while the horizontal axis presents the variety of thematic areas discovered in our study through direct citation analysis i.e.: (1) 'motivation in physical education', (2) 'physical education programmes', (3) 'development of physical education', (4) 'selfdetermination in physical education', (5) 'physical education and students' academic achievement', (6) 'support of physical activity autonomy', (7) 'gender and physical education', and (8) 'long-term effects of physical education'. Combining the two aforementioned dimensions, the matrix may be useful for mapping the literature output in the physical education research field. For instance, the article by Ntoumanis (2001) [16] may be categorized within the thematic cluster dealing with self-determination theory in physical education (in the horizontal dimension) and simultaneously in the field corresponding to studies of adolescents (in the vertical dimension) (cf. Figure 7). Referring to the emerging topics, identified by Tomanek and Lis (2020), which include such issues as: "(1) 'physical education teachers and their training/education', (2) 'physical education in the tertiary education context', (3) 'physical education in the secondary education context" [2], replacing or supplementing age categories with the corresponding levels of education may be recommended.

\section{Conclusions}

In response to the first research question, we have recognized the most influential publications within the research field. The study of the effects of the SPARK physical education program in regard to physical activity of elementary school pupils by Sallis et al. (1997) is found to be the most cited publication in the physical education research field. The systematic literature review and metaanalysis of research on application of self-determination theory in the physical education context by Vasconellos et al. (2020) is recognized as the publication of the 


\begin{tabular}{|l|l|l|l|l|l|l|l|l|}
\hline $\begin{array}{l}\text { adults / } \\
\text { tertiary } \\
\text { education }\end{array}$ & & & & & & & & \\
\hline $\begin{array}{l}\text { adolescents/ } \\
\text { secondary } \\
\text { education }\end{array}$ & & & & $\begin{array}{l}\text { e.g. Ntoumanis } \\
\text { (2001) [16] }\end{array}$ & & & & \\
\hline $\begin{array}{l}\text { children } \\
\text { / primary } \\
\text { education }\end{array}$ & & & & & & & & \\
\hline & 1 & 2 & 3 & 4 & 5 & 6 & 7 & 8 \\
\hline
\end{tabular}

Note: (1) motivation in physical education, (2) physical education programmes, (3) development of physical education, (4) self-determination in physical education, (5) physical education and students' academic achievement, (6) support of physical activity autonomy, (7) gender and physical education, and (8) long-term effects of physical education.

Figure 7. Two dimensional matrix mapping the conceptual structure of the physical education research field: Source: Own study based on combination of findings from co-word analysis [2] and direct citation analysis

highest value of the normalized number of citations. The application of self-determination theory of motivation in physical education is the topic attracting a lot of attention of the top cited publications in the field. The prominent and central position of these references is confirmed by the analysis of citation links. In response to the second research question, we have identified the research fronts in physical education studies, which include: (1) 'motivation in physical education', (2) 'physical education programmes', (3) 'development of physical education', (4) 'self-determination in physical education', (5) 'physical education and students' academic achievement', (6) 'support of physical activity autonomy', (7) 'gender and physical education', and (8) 'long-term effects of physical education'.

The study contributes mainly to development of theory through mapping the scientific output within the physical education research field. Identification of core references provides valuable information for the scholars cultivating the field about the most recognized classical works receiving the highest number of citations and 'emerging stars' of the highest normalized number of citations. Such information is crucial for any theoretical reviews regarding the issues of physical education. Discovering research fronts points out the themes of the highest prominence and may be an indication for searching prospective research topics by authors. It is worth highlighting that the study triangulates, through direct citation methodology, the findings from the co-word analysis conducted by Tomanek and Lis (2020) [2]. As already mentioned, the physical education research field still lacks thorough mapping with the use of bibliometric methods. Thus, the study seems to be an unique and highly valuable contribution to the theory development in the field. Development of the matrix to be used for mapping the conceptual structure of the research field is another contribution of the study.

Appreciating quality and added value of the study, its limitations should be made explicit. Firstly, only one research method i.e. direct citation analysis was employed. As far as the conceptual structure of the field is concerned, identified research fronts have been compared and contrasted with findings of earlier publications [2]. Nevertheless, mapping of the intellectual structure has not been triangulated with other methods. Secondly, inherent weaknesses of citation analysis should be taken into account such as: unknown reasons for citing a documents, self-citations etc. [8,9]. Thirdly, Scopus was the only source of bibliometric data used in the research sampling process. Thus, the following lines of effort for further studies may be recommended: (1) employing other citations methods e.g. co-citation analysis [123] and bibliographic coupling [124] to triangulate the findings related to the intellectual networks and research fronts in the field, (2) replicating the study with the use of other source of bibliometric data, including databases showing a higher representation of publications written in languages other than English, and (3) deepening the understanding of the identified research fronts through conducting relevant systematic literature reviews $[125,126]$.

\section{Highlights:}

- The study of the effects of the SPARK physical education program in regard to physical activity of elementary school pupils by Sallis et al. (1997) is found to be the most cited publication in the physical education research field.

- The application of self-determination theory of motivation in physical education is the topic of other most cited publications in the field i.e. the works Standage et al. (2005), Standage et al. (2003), Ntoumanis (2001), and Ntoumanis (2005). The prominent and central position of these references is confirmed by the analysis of citation links - all of them are found to have the highest number of citation links withing the sample. 
- The systematic literature review and meta-analysis of research on application of self-determination theory in the physical education context by Vasconellos et al. (2020) is recognized as the publication of the highest value of the normalized number of citations.

- Normalized citations top rated references combine some very recent documents (2019-2020), highly cited publications from the 1990s and the 2010s and some older items dated as of the 1960s and the 1970s.

- The following research fronts in physical education studies have been identified through direct citation analysis: (1) 'motivation in physical education', (2) 'physical education programmes', (3) 'development of physical education', (4) 'self-determination in physical education', (5) 'physical education and students' academic achievement', (6) 'support of physical activity autonomy', (7) 'gender and physical education', and (8) 'long-term effects of physical education'.

- Combining the research fronts identified with coword analysis and direct citation analysis, the twodimensional matrix mapping the conceptual structure of the physical education research field has been developed. The matrix categorizes publications according to their themes and the age of students / the levels of education, which are the object of the analysed studies.

\section{Conflicts of Interest}

The authors declare no conflict of interest.

\section{References}

1. KirkD.PhysicalEducation Futures.London:Routledge;2009. https://doi.org/10.4324/9780203874622

2. Tomanek M, Lis A. Managing information on the physical education research field: Bibliometric analysis. Phys Educ Students, 2020;24:213-26. https://doi.org/10.15561/20755279.2020.0404

3. Fan B, Gan F. Bibliometric analysis of articles on physical education idea published from 2005 to 2009. Geomatics Inf Sci Wuhan Univ, 2010;35:193-5.

4. Hinojo-Lucena FJ, Aznar-Díaz I, Cáceres-Reche MP, Romero-Rodríguez JM. Análisis cientimétrico de las publicaciones indexadas en journal citation reports sobre educación física. Movimento, 2019;25. https://doi.org/10.22456/1982-8918.88722

5. ZhuJ,LiuW.Ataleoftwodatabases:TheuseofWebofScienceand Scopus in academic papers. Scientometrics, 2020;123:321-35. https://doi.org/10.1007/s11192-020-03387-8

6. Aghaei Chadegani A, Salehi H, Md Yunus MM, Farhadi H, Fooladi M, Farhadi M, et al. A comparison between two main academic literature collections: Web of Science and Scopus databases. Asian Soc Sci, 2013;9:18-26. https://doi.org/10.5539/ass.v9n5p18

7. He Q. Knowledge discovery through co-word analysis. Libr Trends, 1999;48:133-59.

8. Zupic I, Čater T. Bibliometric methods in management and organization. Organ Res Methods, 2015;18:429-72. https://doi.org/10.1177/1094428114562629

9. Smith LC. Citation analysis. Libr Trends, 1981;30:83-106.

10.Boyack KW, Klavans R. Co-citation analysis, bibliographic coupling, and direct citation: Which citation approach represents the research front most accurately? J Am Soc Inf Sci Technol, 2010;61:2389-404. https://doi.org/10.1002/asi.21419

11. Shibata N, Kajikawa Y, Takeda Y, Matsushima $\mathrm{K}$. Detecting emerging research fronts based on topological measures in citation networks of scientific publications.

Technovation, 2008;28:758-75. https://doi.org/10.1016/j.technovation.2008.03.009

12.van Eck NJ, Waltman L. Software survey: VOSviewer, a computer program for bibliometric mapping. Scientometrics, 2010;84:523-38. https://doi.org/10.1007/s11192-009-0146-3

13.van Eck NJ, Waltman L. VOSviewer Manual. 2020.

14.Sallis JF, McKenzie TL, Alcaraz JE, Kolody B, Faucette N, Hovell MF. The effects of a 2-year physical education program (SPARK) on physical activity and fitness in elementary school students. Am J Public Health, 1997;87:1328-34. https://doi.org/10.2105/AJPH.87.8.1328

15. Vasconcellos D, Parker PD, Hilland T, Cinelli R, Owen KB, Kapsal N, et al. Self-determination theory applied to physical education: A systematic review and meta-analysis. $J$ Educ Psychol, 2020;112:1444-69. https://doi.org/10.1037/edu0000420

16.Ntoumanis N. A self-determination approach to the understanding of motivation in physical education. $B r \quad J \quad E d u c$ Psychol, 2001;71:225-42. https://doi.org/10.1348/000709901158497

17.Standage M, Duda JL, Ntoumanis N. A test of self-determination theory in school physical education. $\mathrm{Br} \quad J$ Educ Psychol, 2005;75:411-33. https://doi.org/10.1348/000709904X22359

18.D'elia F. The training of physical education teacher in primary school. J Hum Sport Exerc, 2019;14:S100-4. https://doi.org/10.14198/jhse.2019.14.Proc1.12

19. Standage M, Duda JL, Ntoumanis N. A model of contextual motivation in physical education: Using constructs from self-determination and achievement goal theories to predict physical activity intentions. $J$ Educ Psychol, 2003;95:97-110. https://doi.org/10.1037/0022-0663.95.1.97

20. Rasberry CN, Lee SM, Robin L, Laris BA, Russell LA, Coyle KK, et al. The association between school-based physical activity, including physical education, and academic performance: A systematic review of the literature. Prev Med (Baltim), 2011;52. https://doi.org/10.1016/j.ypmed.2011.01.027

21.Ntoumanis N. A prospective study of participation in optional school physical education using a self-determination theory framework. $J$ Educ Psychol, 2005;97:444-53. https://doi.org/10.1037/0022-0663.97.3.444

22.Sallis JF. Physical education's role in public health. Res $Q$ Exerc Sport, 1991;62:124-37.

23.Henry FM. The academic discipline of physical education. Quest, 1978;29:13-29. https://doi.org/10.1080/00336297.1978.10519907

24.Goudas M, Biddle S, Fox K. Perceived locus of causality, goal orientations, and perceived competence in school physical education classes. Br J Educ Psychol, 1994;64:453-63. https://doi.org/10.1111/j.2044-8279.1994.tb01116.x

25.Trudeau F, Shephard RJ. Physical education, school physical activity, school sports and academic performance. Int $J$ Behav Nutr Phys Act, 2008;5. https://doi.org/10.1186/1479-5868-5-10

26.Corder WO. Effects of physical education on the 
intellectual, physical, and social development of educable mentally retarded boys. Except Child, 1966;32:357-64. https://doi.org/10.1177/001440296603200601

27.Staiano AE, Calvert SL. Exergames for physical education courses: Physical, social, and cognitive benefits. Child Dev Perspect, 2011;5:93-8. https://doi.org/10.1111/j.1750-8606.2011.00162.x

28. Bailey R. Physical education and sport in schools: A review of benefits and outcomes. J Sch Health, 2006;76:397-401. https://doi.org/10.1111/j.1746-1561.2006.00132.x

29.Wilson WJ, Haegele JA, Kelly LE. Revisiting the narrative about least restrictive environment in physical education. Quest, 2020;72:19-32. https://doi.org/10.1080/00336297.2019.1602063

30.Bailey R, Armour K, Kirk D, Jess M, Pickup I, Sandford R. The educational benefits claimed for physical education and school sport: An academic review. Res Pap Educ, 2009;24:1-27. https://doi.org/10.1080/02671520701809817

31.Coe DP, Pivarnik JM, Womack CJ, Reeves MJ, Malina RM. Effect of physical education and activity levels on academic achievement in children. Med Sci Sports Exerc, 2006;38:1515-9. https://doi.org/10.1249/01.mss.0000227537.13175.1b

32.Kirk D. Educational value and models-based practice in physical education. Educ Philos Theory, 2013;45:973-86. https://doi.org/10.1080/00131857.2013.785352

33.Sallis JF, McKenzie TL, Beets MW, Beighle A, Erwin $\mathrm{H}$, Lee S. Physical education's role in public health: Steps forward and backward over 20 years and HOPE for the future. Res $Q$ Exerc Sport, 2012;83:125-35. https://doi.org/10.1080/02701367.2012.10599842

34.Boiché JCS, Sarrazin PG, Grouzet FME, Pelletier LG, Chanal JP. Students' motivational profiles and achievement outcomes in physical education: A self-determination perspective. J Educ Psychol, 2008;100:688-701. https://doi.org/10.1037/0022-0663.100.3.688

35.Cheon SH, Reeve J, Moon IS. Experimentally based, longitudinally designed, teacher-focused intervention to help physical education teachers be more autonomy supportive toward their students. JSport Exerc Psychol, 2012;34:365-96. https://doi.org/10.1123/jsep.34.3.365

36.Cox AE, Smith AL, Williams L. Change in physical education motivation and physical activity behavior during middle school. J Adolesc Heal, 2008;43:506-13. https://doi.org/10.1016/j.jadohealth.2008.04.020

37.Cox A, Williams L. The roles of perceived teacher support, motivational climate, and psychological need satisfaction in students' physical education motivation. J Sport Exerc Psychol, 2008;30:222-39. https://doi.org/10.1123/jsep.30.2.222

38.Ferrer-Caja E, Weiss MR. Predictors of intrinsic motivation among adolescent students in physical education. Res $Q$ Exerc Sport, 2000;71:267-79. https://doi.org/10.1080/02701367.2000.10608907

39.Guan J, Xiang P, McBride R, Bruene A. Achievement goals, socialgoals, and students'reported persistenceand effortinhigh school physical education.J Teach Phys Educ, 2006;25:58-74. https://doi.org/10.1123/jtpe.25.1.58

40.Haerens L, Kirk D, Cardon G, de Bourdeaudhuij I, Vansteenkiste M. Motivational profiles for secondary school physical education and its relationship to the adoption of a physically active lifestyle among university students. Eur Phys Educ Rev, 2010;16:117-39. https://doi.org/10.1177/1356336X10381304

41.Haerens L, Aelterman N, Van den Berghe L, De Meyer
J, Soenens B, Vansteenkiste M. Observing physical education teachers' need-supportive interactions in classroom settings. J Sport Exerc Psychol, 2013;35:3-17. https://doi.org/10.1123/jsep.35.1.3

42.Haerens L, Aelterman N, Vansteenkiste M, Soenens B, Van Petegem S. Do perceived autonomy-supportive and controlling teaching relate to physical education students' motivational experiences through unique pathways? Distinguishing between the bright and dark side of motivation. Psychol Sport Exerc, 2015;16:26-36. https://doi.org/10.1016/j.psychsport.2014.08.013

43.Mouratidis A, Vansteenkiste M, Lens W, Sideridis G. The motivating role of positive feedback in sport and physical education: Evidence for a motivational model. $J$ Sport Exerc Psychol, 2008;30:240-58. https://doi.org/10.1123/jsep.30.2.240

44.Murcia JAM, Coll DGC, Garzón MC. Preliminary validation in Spanish of a scale designed to measure motivation in physical education classes: The perceived locus of causality (PLOC) scale. Span J Psychol, 2009;12:327-37. https://doi.org/10.1017/S1138741600001724

45.Ntoumanis N. Motivational clusters in a sample of British physical education classes. Psychol Sport Exerc, 2002;3:177-94. https://doi.org/10.1016/S1469-0292(01)00020-6

46.Ntoumanis N, Pensgaard AM, Martin C, Pipe K. An idiographic analysis of amotivation in compulsory school physical education. J Sport Exerc Psychol, 2004;26:197-214. https://doi.org/10.1123/jsep.26.2.197

47.Ntoumanis N, Standage M. Motivation in physical education classes: A self-determination theory perspective. Theory Res Educ, 2009;7:194-202. https://doi.org/10.1177/1477878509104324

48.Standage M, Duda JL, Ntoumanis N. Students' motivational processes and their relationship to teacher ratings in school physical education: A self-determination theory approach. Res $Q$ Exerc Sport, 2006;77:100-10. https://doi.org/10.1080/02701367.2006.10599336

49.Taylor IM, Ntoumanis N. Teacher motivational strategies and student self-determination in physical education. $J$ Educ Psychol, 2007;99:747-60. https://doi.org/10.1037/0022-0663.99.4.747

50.TaylorIM, Ntoumanis N, Standage M, Spray CM. Motivational predictors of physical education students' effort, exercise intentions, and leisure-time physical activity: A multilevel lineargrowthanalysis.JSportExercPsychol, 2010;32:99-120. https://doi.org/10.1123/jsep.32.1.99

51.Tessier D, Sarrazin P, Ntoumanis N. The effect of an intervention to improve newly qualified teachers' interpersonal style, students motivation and psychological need satisfaction in sport-based physical education. Contemp Educ Psychol, 2010;35:242-53. https://doi.org/10.1016/j.cedpsych.2010.05.005

52.Van den Berghe L, Vansteenkiste M, Cardon G, Kirk D, Haerens L. Research on self-determination in physical education: Key findings and proposals for future research. Phys Educ Sport Pedagog, 2014;19:97-121. https://doi.org/10.1080/17408989.2012.732563

53.Belsky J, Booth C, Bradley R, Brownell CA, Campbell SB, Clarke-Stewart A, et al. Frequency and intensity of activity of third-grade children in physical education. Arch Pediatr Adolesc Med, 2003;157:185-90. https://doi.org/10.1001/archpedi.157.2.185

54.Burgeson CR, Wechsler H, Brener ND, Young JC, Spain CG. Physical education and activity: Results 
from the School Health Policies and Programs Study 2000. J Sch Health, 2001;71:279-93. https://doi.org/10.1111/j.1746-1561.2001.tb03505.x

55.Cawleya J, Meyerhoefer C, Newhouse D. The impact of state physical education requirements on youth physical activity and overweight. Health Econ, 2007;16:1287-301. https://doi.org/10.1002/hec.1218

56.Datar A, Sturm R. Physical education in elementary school and body mass index: Evidence from the early childhood longitudinal study. Am J Public Health, 2004;94:1501-6. https://doi.org/10.2105/AJPH.94.9.1501

57.Fairclough S, Stratton G. Physical activity levels in middle and high school physical education: A review. Pediatr Exerc Sci, 2005;17:217-36. https://doi.org/10.1123/pes.17.3.217

58.Hills AP, Dengel DR, Lubans DR. Supporting public health priorities: Recommendations for physical education and physical activity promotion in schools. Prog Cardiovasc Dis, 2015;57:368-74. https://doi.org/10.1016/j.pcad.2014.09.010

59.LeeSM,BurgesonCR,FultonJE, SpainCG.Physicaleducation and physical activity: Results from the School Health Policies and Programs Study 2006. J Sch Health, 2007;77:435-63. https://doi.org/10.1111/j.1746-1561.2007.00229.x

60.Lonsdale C, Rosenkranz RR, Peralta LR, Bennie A, Fahey P, Lubans DR. A systematic review and metaanalysis of interventions designed to increase moderateto-vigorous physical activity in school physical education lessons. Prev Med (Baltim), 2013;56:152-61. https://doi.org/10.1016/j.ypmed.2012.12.004

61.Marshall J, Hardman K. The state and status of physical education in schools in international context. Eur Phys Educ Rev, 2000;6:203-29. https://doi.org/10.1177/1356336X000063001

62.McKenzie TL, Feldman H, Woods SE, Romero KA, Dahlstrom V, Stone EJ, et al. Children activity levels and lesson context during third-grade physical education. Res $Q$ Exerc Sport, 1995;66:184-93. https://doi.org/10.1080/02701367.1995.10608832

63.McKenzie TL, Nader PR, Strikmiller PK, Yang M, Stone EJ, Perry CL, et al. School physical education: Effect of the child and adolescent trial for cardiovascular health. Prev Med (Baltim), 1996;25:423-31. https://doi.org/10.1006/pmed.1996.0074

64.McKenzie TL, Sallis JF, Prochaska JJ, Conway TL, Marshall SJ, Rosengard P. Evaluation of a twoyear middle-school physical education intervention: M-SPAN. Med Sci Sports Exerc, 2004;36:1382-8. https://doi.org/10.1249/01.MSS.0000135792.20358.4D

65.Mckenzie TL, Lounsbery MAF. School physical education: The pill not taken. Am J Lifestyle Med, 2009;3:219-25. https://doi.org/10.1177/1559827609331562

66. Morgan PJ, Hansen V. Classroom teachers' perceptions of the impact of barriers to teaching physical education on the quality of physical education programs. Res $Q$ Exerc Sport, 2008;79:506-16. https://doi.org/10.1080/02701367.2008.10599517

67.Nettlefold L, McKay HA, Warburton DER, McGuire KA, Bredin SSD, Naylor PJ. The challenge of low physical activity during the school day: At recess, lunch and in physical education. $\mathrm{Br} J$ Sports Med, 2011;45:813-9. https://doi.org/10.1136/bjsm.2009.068072

68.Sallis JF, McKenzie TL, Alcaraz JE, Kolody B, Hovell MF, Nader PR. Project SPARK: Effects of physical education on adiposity in children. Ann NY Acad Sci, 1993;699:127-36. https://doi.org/10.1111/j.1749-6632.1993.tb18844.x

69.Trudeau F, Laurencelle L, Tremblay J, Rajic M, Shephard RJ. Daily primary school physical education: Effects on physical activity during adult life.Med SciSports Exerc, 1999;31:111-7. https://doi.org/10.1097/00005768-199901000-00018

70.Van Beurden E, Barnett LM, Zask A, Dietrich UC, Brooks LO, Beard J. Can we skill and activate children through primary school physical education lessons? "Move it Groove it" - A collaborative health promotion intervention. Prev Med (Baltim), 2003;36:493-501. https://doi.org/10.1016/S0091-7435(02)00044-0

71.Armour KM, Yelling MR. Continuing professional development for experienced physical education teachers: Towards effective provision. Sport Educ Soc, 2004;9:95-114. https://doi.org/10.1080/1357332042000175836

72.Armour KM, Yelling M. Effective professional development for physical education teachers: The role of informal, collaborative learning. J Teach Phys Educ, 2007;26:177-200. https://doi.org/10.1123/jtpe.26.2.177

73.Bailey R. Evaluating the relationship between physical education, sportand socialinclusion.EducRev, 2005;57:71-90. https://doi.org/10.1080/0013191042000274196

74.Gard M, Wright J. Managing uncertainty: Obesity discourses and physical education in a risk society. Stud Philos Educ, 2001;20:535-49. https://doi.org/10.1023/A:1012238617836

75.Gorely T, Holroyd R, Kirk D. Muscularity, the habitus and the social construction of gender: Towards a gender-relevant physical education. Br J Sociol Educ, 2003;24:429-48. https://doi.org/10.1080/01425690301923

76.Kirk D, Colquhoun D. Healthism and physical education. $\quad B r \quad J$ Sociol Educ, 1989;10:417-34. https://doi.org/10.1080/0142569890100403

77.Kirk D, Macdonald D. Situated learning in physical education. $J$ Teach Phys Educ, 1998;17:376-87. https://doi.org/10.1123/jtpe.17.3.376

78.Kirk D. Physical culture, physical education and relational analysis. Sport Educ Soc, 1999;4:63-73. https://doi.org/10.1080/1357332990040105

79.Kirk D. The "obesity crisis" and school physical education. Sport Educ Soc, 2006;11:121-33. https://doi.org/10.1080/13573320600640660

80.Light R. Complex learning theory-its epistemology and its assumptions about learning: Implications for physical education. $J$ Teach Phys Educ, 2008;27:21-37. https://doi.org/10.1123/jtpe.27.1.21

81.Penney D, Chandler T. Physical education: What future(s)? Sport Educ Soc, 2000;5:71-87. https://doi.org/10.1080/135733200114442

82.Siedentop D. Content knowledge for physical education. J Teach Phys Educ 2002;21:368-77. https://doi.org/10.1123/ jtpe.21.4.368

83.Digelidis N, Papaioannou A, Laparidis K, Christodoulidis T. A one-year intervention in 7th grade physical education classes aiming to change motivational climate and attitudes towards exercise. Psychol Sport Exerc, 2003;4:195-210. https://doi.org/10.1016/S1469-0292(02)00002-X

84.Duda JL. Maximizing motivation in sport and physical education among children and adolescents: The case for greater task involvement. Quest, 1996;48:290-302. https://doi.org/10.1080/00336297.1996.10484198

85.Goudas M, Biddle S. Perceived motivational climate and intrinsic motivation in school physical education classes. Eur $J$ Psychol Educ, 1994;9:241-50. https://doi.org/10.1007/BF03172783 
86.Papaioannou A. Development of a questionnaire to measure achievement orientations in physical education. Res $Q$ Exerc Sport, 1994;65:11-20. https://doi.org/10.1080/02701367.1994.10762203

87.Papaioannou A, Marsh HW, Theodorakis Y. A multilevel approach to motivational climate in physical education and sport settings: An individual or a group level construct? J Sport Exerc Psychol, 2004;26:90-118. https://doi.org/10.1123/jsep.26.1.90

88.Solmon MA. Impact of motivational climate on students' behaviors and perceptions in a physical education setting. $J$ Educ Psychol, 1996;88:731-8. https://doi.org/10.1037/0022-0663.88.4.731

89.Standage M, Treasure DC. Relationship among achievement goal orientations and multidimensional situational motivation in physical education. Br J Educ Psychol, 2002;72:87-103. https://doi.org/10.1348/000709902158784

90.Standage M, Duda JL, Ntoumanis N. Predicting motivational regulations in physical education: The interplay between dispositional goal orientations, motivational climate and perceived competence. J Sports Sci, 2003;21:631-47. https://doi.org/10.1080/0264041031000101962

91.Taylor IM, Ntoumanis N, Standage M. A selfdetermination theory approach to understanding the antecedents of teachers' motivational strategies in physical education. $J$ Sport Exerc Psychol, 2008;30:75-94. https://doi.org/10.1123/jsep.30.1.75

92.Treasure DC, Roberts GC. Applications of achievement goal theory to physical education: Implications for enhancing motivation. Quest, 1995;47:475-89. https://doi.org/10.1080/00336297.1995.10484170

93. Wallhead TL, Ntoumanis N. Effects of a sport education intervention on students' motivational responses in physical education. $J$ Teach Phys Educ, 2004;23:4-18. https://doi.org/10.1123/jtpe.23.1.4

94.Wang CKJ, Chatzisarantis NLD, Spray CM, Biddle SJH. Achievement goal profiles in school physical education: Differences in self-determination, sport ability beliefs, and physical activity. Br J Educ Psychol, 2002;72:433-45. https://doi.org/10.1348/000709902320634401

95.Wang CKJ, Biddle SJH, Elliot AJ. The $2 \times 2$ achievement goal framework in a physical education context. Psychol Sport Exerc, 2007;8:147-68. https://doi.org/10.1016/j.psychsport.2005.08.012

96.Ardoy DN, Fernández-Rodríguez JM, JiménezPavón D, Castillo R, Ruiz JR, Ortega FB. A physical education trial improves adolescents' cognitive performance and academic achievement: The EDUFIT study. Scand J Med Sci Sport, 2014;24. https://doi.org/10.1111/sms.12093

97.Carlson SA, Fulton JE, Lee SM, Maynard LM, Brown DR, Kohl HW, et al. Physical education and academic achievement in elementary school: Data from the early childhood longitudinal study. Am J Public Health, 2008;98:721-7. https://doi.org/10.2105/AJPH.2007.117176

98.Fairclough S, Stratton G. "Physical education makes you fit and healthy". Physical education's contribution to young people's physical activity levels. Health Educ Res, 2005;20:14-23. https://doi.org/10.1093/her/cyg101

99.Gibbons SL, Ebbeck V, Weiss MR. Fair Play for Kids: Effects on the moral development of children in physical education. Res $Q$ Exerc Sport, 1995;66:247-55. https://doi.org/10.1080/02701367.1995.10608839

100. Sallis JF, Lewis M, McKenzie TL, Kolody B, Marshall S, Rosengard P. Effects of health-related physical education on academic achievement: Project SPARK. Res Q Exerc Sport, 1999;70:127-34. https://doi.org/10.1080/02701367.1999.10608030

101. Chatzisarantis NLD, Hagger MS, Biddle SJH, Smith B, Wang JCK. A meta-analysis of perceived locus of causality in exercise, sport, and physical education contexts. J Sport Exerc Psychol, 2003;25:284-306. https://doi.org/10.1123/jsep.25.3.284

102. Hagger MS, Culverhouse T, Chatzisarantis NLD, Biddle SJH. The processes by which perceived autonomy support in physical education promotes leisure-time physical activity intentions and behavior: A transcontextual model. $J$ Educ Psychol, 2003;95:784-95. https://doi.org/10.1037/0022-0663.95.4.784

103. Hagger MS, Barkoukis V, Chatzisarantis NLD, John Wang CK, Baranowski J. Perceived autonomy support in physical education and leisure-time physical activity: A cross-cultural evaluation of the transcontextual model. $J$ Educ Psychol, 2005;97:376-90. https://doi.org/10.1037/0022-0663.97.3.376

104. Hagger M, Chatzisarantis NLD, Hein V, Soós I, Karsai I, Lintunen $\mathrm{T}$, et al. Teacher, peer and parent autonomy support in physical education and leisure-time physical activity: A trans-contextual model of motivation in four nations. Psychol Heal, 2009;24:689-711. https://doi.org/10.1080/08870440801956192

105. Lim BSC, Wang CKJ. Perceived autonomy support, behavioural regulations in physical education and physical activity intention. Psychol Sport Exerc, 2009;10:52-60. https://doi.org/10.1016/j.psychsport.2008.06.003

106. Lonsdale C, Sabiston CM, Raedeke TD, Ha ASC, Sum RKW. Self-determined motivation and students' physical activity during structured physical education lessons and free choice periods. Prev Med (Baltim), 2009;48:69-73. https://doi.org/10.1016/j.ypmed.2008.09.013

107. Standage M, Gillison FB, Ntoumanis N, Treasure DC. Predicting students' physical activity and health-related well-being: A prospective cross-domain investigation of motivation across school physical education and exercise settings. J Sport Exerc Psychol, 2012;34:37-60. https://doi.org/10.1123/jsep.34.1.37

108. Azzarito L, Solomon MA. A reconceptualization of physical education: The intersection of gender/ race/social class. Sport Educ Soc, 2005;10:25-47. https://doi.org/10.1080/135733205200028794

109. Block ME, Obrusnikova I. Inclusion in physical education: A review of the literature from 19952005. Adapt Phys Act Q, 2007;24:103-24. https://doi.org/10.1123/apaq.24.2.103

110. Cockburn C, Clarke G. "Everybody's looking at you!": Girls negotiating the "femininity deficit" they incur in physical education. Womens Stud Int Forum, 2002;25:651-65. https://doi.org/10.1016/S0277-5395(02)00351-5

111. Flintoff A, Fitzgerald H, Scraton S. The challenges of intersectionality: Researching difference in physical education. Int Stud Sociol Educ, 2008;18:73-85. https://doi.org/10.1080/09620210802351300

112. Garrett R. Negotiating a physical identity: Girls, bodies and physical education. Sport Educ Soc, 2004;9:223-37. https://doi.org/10.1080/1357332042000233958

113. Goodwin DL, Watkinson EJ. Inclusive physical education from the perspective of students with physical disabilities. Adapt Phys Act Q, 2000;17:144-60. https://doi.org/10.1123/apaq.17.2.144

114. McKenzie TL, Marshall SJ, Sallis JF, Conway 
TL. Student activity levels, lesson context, and teacher behavior during middle school physical education. Res $Q$ Exerc Sport, 2000;71:249-59. https://doi.org/10.1080/02701367.2000.10608905

115. Curtner-Smith MD. The more things change the more they stay the same: Factors influencing teachers' interpretations and delivery of national curriculum physical education. Sport Educ Soc, 1999;4:75-97. https://doi.org/10.1080/1357332990040106

116. Curtner-Smith MD. The occupational socialization of a first-year physical eductaion teacher with a teaching orientation. Sport Educ Soc, 2001;6:81-105. https://doi.org/10.1080/713696040

117. Enright E, O'Sullivan M. "Can I do it in my pyjamas?" Negotiating a physical education curriculum with teenage girls. Eur Phys Educ Rev, 2010;16:203-22. https://doi.org/10.1177/1356336X10382967

118. Flintoff A, Scraton S. Stepping into active leisure? Young women's perceptions of active lifestyles and their experiences of school physical education. Sport Educ Soc, 2001;6:5-21. https://doi.org/10.1080/713696043

119. Kirk D. Physical education, youth sport and lifelong participation: The importance of early learning experiences. Eur Phys Educ Rev, 2005;11:239-55. https://doi.org/10.1177/1356336X05056649
120. McKenzie TL, Sallis JF, Kolody B, Faucette FN. Long-term effectsofaphysicaleducationcurriculumandstaffdevelopment program: SPARK. Res Q Exerc Sport, 1997;68:280-91. https://doi.org/10.1080/02701367.1997.10608009

121. Parker A. The construction of masculinity within boys' physical education. Gend Educ, 1996;8:141-58. https://doi.org/10.1080/09540259650038824

122. Ames C. Classrooms: Goals, structures, and student motivation. $J$ Educ Psychol, 1992;84:261-71. https://doi.org/10.1037/0022-0663.84.3.261

123. Small H. Co-citation in the scientific literature: A new measure of the relationship between two documents. $J$ Am Soc Inf Sci, 1973;24:265-9. https://doi.org/10.1002/asi.4630240406

124. Kessler MM. Bibliographic coupling between scientific papers. Am Doc, 1963;14:10-25. https://doi.org/doi:10.1002/asi.5090140103

125. Tranfield D, Denyer D, Smart P. Towards a methodology for developing evidence-informed management knowledge by means of systematic review. Br J Manag, 2003;14:207-22. https://doi.org/10.1111/1467-8551.00375

126. Booth A, Sutton A, Papaioannou D. Systematic Approaches to a Successful Literature Review. London: Sage; 2012.

\section{Information about the authors:}

Andrzej Lis; https://orcid.org/0000-0003-4080-4137; andrzejlis@econ.umk.pl; Faculty of Economic Sciences and Management, Nicolaus Copernicus University; ul. Gagarina 13a, 87-100, Toruń, Poland.

Mateusz Tomanek; (Corresponding Author); https://orcid.org/0000-0002-9527-2513; mtomanek@umk.pl; Faculty of Economic Sciences and Management, Nicolaus Copernicus University; ul. Gagarina 13a, 87-100, Toruń, Poland.

Cite this article as:

Lis A, Tomanek M. Mapping the intellectual and conceptual structure of physical education research: Direct citation analysis.. Physical Education of Students, 2021;25(2):67-84. https://doi.org/10.15561/20755279.2021.0201

This is an Open Access article distributed under the terms of the Creative Commons Attribution License, which permits unrestricted use, distribution, and reproduction in any medium, provided the original work is properly cited http://creativecommons.org/licenses/by/4.0/deed.en

Received: 21.12.2020

Accepted: 21.01.2021; Published: 30.04.2021 